\title{
COMMUNITY ACQUIRED PNEUMONIA, RISK FACTORS AND MORTALITY IN PATIENTS ADMITTED TO INTERNAL MEDICINE ICU UNIT, AI AZHAR UNIVERSITY'S HOSPITALS
}

AHMED MOHAMED ABOHASSAN ${ }^{1}$ AND MAHMOUD A. HASHISH ${ }^{2}$

Departments of Internal Medicine ${ }^{1}$ and Clinical Pathology ${ }^{2}$, Faculty of Medicine, Al-Azhar University, Nasr City, Egypt ( ${ }^{*}$ Correspondence: boosyzaza@gmail.com)

\section{Abstract}

Pneumonia is one of the leading cause of death - Previous studies considered that advanced age, renal failure, heart failure, septic shock and acute respiratory distress syndrome as significant risk factors for pneumonia: Despite the high mortality in patients with pneumonia admitted to an ICU, the risk factors data for death remain limited.

A total of 90 of community-acquired pneumonia patients aged $\geq 30$ years at Al Hussein University Hospital from September 2017 to December 2018 were studied. They suffered from acute illness and evidence of consolidation on a chest radiograph. Risk factors related to sociodemographic factors, drug use, clinical history were investigated by questionnaire, laboratory assays, radiological assay and culture and sensitivity and statistically analysis

The results showed high mortality especially among elderly patients and those with neoplastic disease or chronic renal failure. The other prognostic factors related to increased mortality included mechanical ventilation, acute respiratory distress syndrome (ARDS), acute renal failure, septicemia, and septic shock. Mortality rate was 40/90 patients. Age, under body weight, smocking, chronic illness as diabetes, heart disease, renal disease

Keywords: Risk factors, ICU unit, Community acquired pneumonia

\section{Introduction}

Community acquired pneumonia (CAP) is an acute lower respiratory tract infection (cough with lower respiratory tract symptoms as chest pain or dyspnea) and systemic manifestations $\left(>38^{\mathrm{O}} \mathrm{C}\right.$, shivers $\&$ aches) and consolidation or new radiographic shadow on chest radiography, sweating and fevers (Mandell et al, 2007).

Critically patients with CAP as confusion, high urea, high respiratory rate, low blood pressure (CURB) and some studies add age above 65 to be(CURP + age 65) risk class 35 upon admission (Dellinger et al, 2008)

Major criteria for CAP were under mechanical ventilation and developed septic shock needed levodopa (Liapikou et al, 2009). Minor criteria for CAP (respiratory rate $>30$ cycles/min, arterial oxygen partial pressure/ fractional inspired oxygen $(\mathrm{PaO} 2 / \mathrm{FiO} 2)<$ $250 \mathrm{mmHg}$, multi-lobes pneumonia, coma or conscious impaired level, BUN level $>20$ $\mathrm{mg} / \mathrm{dl}$, WBC count $<4 \times 109$ cells/l), platelet count $<100 \times 109 / 1,<36^{\circ} \mathrm{C}$, SBP $<90 \mathrm{mmHg}$ $\&$ required large amount of fluid, 2 majors or
3 minor indicated risky criteria (Rello et al, 2009).

The adult respiratory distress syndrome (ARDS) is acute onset of bilateral pneumonia, $\mathrm{PaO} 2 / \mathrm{FiO} 250 \mathrm{mmHg}$, pulmonary artery wedge pressure $<18 \mathrm{mmHgwithout} \mathrm{left} \mathrm{ventric-}$ ular failure. The acute renal failure (ARF) increased serum creatinine level $(>4 \mathrm{mg} / \mathrm{dl})$ with $75 \%$, glomerular filtration rate reduction and urine output $<0.3 \mathrm{ml} / \mathrm{kg} / 24 \mathrm{hr}$, or anuria for $12 \mathrm{hrs}$ (Brower et al, 2004). CURB-65 score (confusion, blood urea $>42,8 \mathrm{mg} / \mathrm{dl}$, respiratory rate $>30 / \mathrm{min}$, blood pressure $<90 /$ $60 \mathrm{mmHg}$, age $>65$ ) indicated hospitalization (Lim et al, 2001). But, community acquired pneumonia (CAP) was life-threatened nosocomial and required ICU admission (Kamath et al, 2006), with mortality rates $20-50 \%$ (Trotter et al, 2008).

The HAP occurred at a rate of 5-10/1000 at hospital admissions (Kalil et al, 2016), without difference in mortality rate among ventilator associated pneumonia (VAP) as to short or long antibiotic course (Pugh et al, 2015). Vaccines and publication guide lines 
to manage nosocomial pneumonia mortality rate was 15 to $50 \%$ (Vallés et al, 2014).

Relapse of pneumonia was initial causative organism associated with the clinical or radiological pneumonia signs post treatment (Fekih et al, 2009). CAP was responsible for most infectious disease worldwide, with advanced diagnosis and management, yet there were gaps to improve recurrence and relapse or pneumonia (Ranzani et al, 2019).

The work aimed to study the risk factors to the community acquired pneumonia mortality and morbidity in patients admitted to the Internal Medicine ICU Unit, Al Azhar University's Hospitals .

\section{Patients and Methods}

Nighty patients (60 males \& 30 females, aged between 35 to 72 years) with community acquired pneumonia attendant the ICU, from September 2017 to December 2018 were selected, with ethical consent from patients or their relatives.

Patients were subjected medical sheets with stress on smoking, alcoholism; chronic obstructive pulmonary disease (COPD), diabetes mellitus, chronic cardiac diseases, chronic renal failure, chronic neurologic diseases, chronic liver diseases, neoplasm, steroi$\mathrm{ds}$, and immuno-suppressive drugs. Acute physiology and chronic health evaluation II (APACHE II) were scored. CAP symptoms were evaluated for vital signs at the admission, CT scan radiology \& mechanical ventilation need (Estenssoro and Dubin, 2016)

Laboratory examinations: $\mathrm{CBC}, \mathrm{C}$ reactive protein, prothrombin time, prothrombin concentration, serum sodium, potassium, urea, creatinine, AST, ALT \& arterial blood gases as well as gram stain, culture, and sensitivity of blood and sputum, as well as stool analysis to identified pneumonia causative agent

Exclusion criteria were patients on immunosuppressive drugs and corticosteroids for more than 30 days or leukocyte counts < 1000 cells $/ \mathrm{ml}$ or neutrophils $<500$ cells $/ \mathrm{ml}$ ), extra-pulmonary infection as bacteremia and endocarditis, lung complications as abscess and/or fibrosis or patients with septic shock.

\section{Results}

There was significant difference between groups regarding to vital signs as non survivors patients were hypertensive $(100 \pm 30)$, tachycardia (120 \pm 20$)$ normal to low body temperatures $(36.5 \pm 1.3)$, high respiratory rate $(35 \pm 10) \&$ low Pao2/Fio2 (90 \pm 75$)$.

Most of the patients were anemic with hemoglobin (9.7 \pm 3.1$)$, high $\mathrm{CRP}(480 \pm 120)$, high total leucocytes $(14.2 \pm 5.2)$, normal platelet count $(210 \pm 130)$, high renal function with blood urea $(62 \pm 15)$ and serum creatinine $(2.3 \pm 1.6)$, but normal serum sodium, \& potassium $(140 \pm 7,3.6 \pm 1.4,32 \pm 15)$.

Most of the patients were represented by bilateral and multinodular pneumonia in need of mechanical ventilation (98\% non-survivors) and (60\% survivors). About $30 \%$ of patients developed ARDS in non-survivors and $2 \%$ in survivors and other risk factors as renal failure and neoplasia; the mortality rate was high $(40 \%)$. Admitted cases due to microbial infections were only 54(60\%).

There was high significant difference as to age survivors $(40 \pm 14)$, and non survivors $(65 \pm 12)$, and non survivors smoking was a risk factor for mortality (80\%). Other medical problem as cardiac disease, renal disease, liver disease, neoplastic problem, or previous stroke was a risk factors for mortality in pneumonia patients high significant difference between survivors and non-survivors. Non-survivors developed septicemia (50\%) compared to survivors $(6 \%)$. Patients received corticosteroid and cytotoxic drugs has high mortality rate as 4 cases $(10 \%$ of total death) died and patients received cytotoxic drugs only five with $80 \%$ death and one case $(2 \%)$ of this group survived. There was high significant difference between study groups regarding to CIRB score.

Non-survivor patients on admission special maneuvers used the vasopressor and inotropes (75\%) and vasopressors and inotropes in $9(18 \%)$ survivors' patients. Regarding to dialysis 6 patients $(15 \%)$ in nonsurvivors need dialysis and one case $(2 \%)$ needed dialysis. six cases (15\%) needed blo- 
od transfusion was done but only one case $(2 \%)$ in survivors needed blood transfusion.
39 patients $(98 \%)$ in non-survivors and 30 patients $(60 \%)$ in survivors ones. Details were given in tables $(1,2,3,4 \& 5)$.

Table 1: Comparison between survivors and non-survivors regarding to vital signs

\begin{tabular}{|l|c|c|c|c|}
\hline Data & Non-Survivors & Survivors & T test & P value \\
\hline Body temperature $\left({ }^{\circ} \mathrm{C}\right)$ & $36 \cdot 5 \pm 1 \cdot 3$ & $38 \pm 1 \cdot 2$ & -8.38 & $<0 \cdot 0001$ \\
\hline Systolic blood pressure $(\mathrm{mmHg})$ & $100 \pm 30$ & $130 \pm 20$ & -6.255 & $<0 \cdot 0001$ \\
\hline Heart rate (beats/min) & $120 \pm 20$ & $100 \pm 15$ & -5.989 & $<0 \cdot 0001$ \\
\hline Respiratory rate (breaths/min) & $35 \pm 10$ & $22 \pm 5$ & -8.356 & $<0 \cdot 0001$ \\
\hline $\mathrm{PaO} 2 / \mathrm{FiO} 2 \leq 250(\mathrm{mmHg}) \mathrm{c}$ & $90(75)$ & $550(35)$ & -42.3 & $<0 \cdot 00001$ \\
\hline
\end{tabular}

Table 2: Comparative laboratory investigation among patients

\begin{tabular}{|l|c|c|c|c|}
\hline Data of the patients & Non-Survivors & Survivors & T test & P value \\
\hline Hemoglobin $(\mathrm{g} / \mathrm{dl})$ & $9 \cdot 7 \pm 3 \cdot 1$ & $12.7 \pm 2.3$ & 5.666 & $<0.0001$ \\
\hline Total leukocyte count $(\times 109 / \mathrm{l})$ & $14 \cdot 2 \pm 5 \cdot 2$ & $18.7 \pm 2.4$ & 5.639 & $<0.0001$ \\
\hline Platelets $(\times 109 / \mathrm{l})$ & $210 \pm 130$ & $220 \pm 30$ & 0.578 & $>0.28$ \\
\hline C-reactive protein $(\mathrm{mg} / \mathrm{dl})$ & $480 \pm 120$ & $470 \pm 130$ & 0.416 & $>0.34$ \\
\hline Serum sodium $(\mathrm{mmol} / \mathrm{l})$ & $140 \pm 7$ & $137 \pm 3$ & 3.005 & $>0.002$ \\
\hline Serum potassium $(\mathrm{mmol} / \mathrm{l})$ & $4 \cdot 6 \pm 1 \cdot 3$ & $4.1 \pm 0.9$ & 2.374 & $>0.0001$ \\
\hline Serum urea $(\mathrm{mg} / \mathrm{dl})$ & $62 \pm 15$ & $35 \pm 7$ & 11.55 & $<00001$ \\
\hline Serum creatinine $(\mathrm{mg} / \mathrm{dl})$ & $2 \cdot 3 \pm 0.6$ & $1.3 \pm 0.3$ & 11.323 & $<00001$ \\
\hline
\end{tabular}

Table 3: Laboratory and radiological results among patients

\begin{tabular}{|l|c|c|}
\hline \multicolumn{1}{|c|}{ Data } & number & Percent \\
\hline Bilateral/multilobar infiltrate in Chest X Ray & 54 & $60 \%$ \\
\hline Shock at admission & 27 & $30 \%$ \\
\hline Microbial identification & 54 & $60 \%$ \\
\hline Overall mortality & 36 & $40 \%$ \\
\hline
\end{tabular}

Table 4: Comparison between survivors (50) and non-survivors (40) as to risk factors

\begin{tabular}{|l|l|l|l|l|}
\hline Variables & Non-survivors & Survivors & Chi square & $\mathrm{p}$ value \\
\hline Age, years & $65 \pm 12$ & $40 \pm 14$ & $\mathrm{~T}=1.98$ & $\leq 0 \cdot 03$ \\
\hline Smokers & $80 \%(32)$ & $24 \%(12)$ & 39.38 & $\leq 0 \cdot 00001$ \\
\hline Body mass index & $16 \pm 3 \%$ & $24 \pm 4 \%$ & 11.97 & $<0.00001$ \\
\hline Neoplastic disease & $5 \%(2)$ & $0.5 \%(1)$ & 1.4615 & $\leq 0 \cdot 23$ \\
\hline Liver disease & $25 \%(10)$ & $6 \%(3)$ & 5.888 & $<0.02$ \\
\hline Congestive heart failure & $45 \%(15)$ & $6 \%(3)$ & 7.1938 & $\leq 0 \cdot 007$ \\
\hline Cerebral stroke & $10 \%(4)$ & $6 \%(3)$ & 2.1213 & $\leq 0 \cdot 202$ \\
\hline Chronic renal disease & $40 \%(16)$ & $6 \%(3)$ & 8.15 & $\leq 0 \cdot 04$ \\
\hline Immunosuppression & $10 \%(4)$ & $2 \%(1)$ & 0.8595 & $\leq 0 \cdot 35$ \\
\hline Septicemia & $50 \%(20)$ & $6 \%(3)$ & 18.2838 & $\leq 0 \cdot 002$ \\
\hline Acute renal failure & $75 \%(30)$ & $30 \%(15)$ & 20.4 & $\leq 0 \cdot 00001$ \\
\hline Bacteremia & $30 \%(12)$ & $6 \%(3)$ & 7.1938 & $\leq 0 \cdot 007$ \\
\hline Mechanical ventilation & $98 \%(38)$ & $60 \%(30)$ & 21.76 & $\leq 0 \cdot 00001$ \\
\hline ARDS & $30 \%(12)$ & $2 \%(1)$ & 22.94 & $\leq 0 \cdot 00001$ \\
\hline CURB scores 1 and 2. & $30 \%(12)$ & $70 \%(35)$ & 22.275 & $\leq 0 \cdot 00001$ \\
CURB scores 3, 4 and 5 & $70 \%(30)$ & $30 \%(15)$ & & \\
\hline
\end{tabular}

Table 5: Management other than antibiotics and oxygen among groups

\begin{tabular}{|l|c|c|c|c|}
\hline Intervention & Non-Survivors & Survivors & T test & P value \\
\hline Inotropes/vasopressors & $75 \%(30)$ & $18 \%(9)$ & 24.133 & $\leq 0 \cdot 00001$ \\
\hline Dialysis & $15 \%(6)$ & $2 \%(1)$ & 0.8595 & $\leq 0 \cdot 35$ \\
\hline Red blood cell transfusion & $15 \%(6)$ & $2 \%(1)$ & 4.88 & $\leq 0 \cdot 03$ \\
\hline Central venous catheterization & $98 \%(38)$ & $60 \%(30)$ & 22.4245 & $\leq 0 \cdot 00001$ \\
\hline
\end{tabular}

\section{Discussion}

The respiratory infections led to significant mortality and morbidity in critically sick patients with the advances in the ventilation strategies and novel development antimicrobial antibotics (Alotair et al, 2015). Symptoms of bronchopneumonia may be like oth- er types of pneumonia. This condition often began with flu-like symptoms that could become more severe over a few days, symptoms included fever, a cough that brings up mucus, shortness of breath, chest pain, rapid breathing, sweating, chills, headaches, muscle aches, pleurisy, or chest pain that results 
from inflammation due to excessive coughing, fatigue, confusion or delirium, especially in older people (Franco, 2017)

Generally speaking, bacteria, viruses, fungi, and parasites cause pneumonia (Brochot et al, 2017). Also, all these causative agents were potential cause of the acute neonatal pneumonia, transmitted vertically from the mother or acquired from the postnatal environment (Hooven and Polin, 2017).

The infection causes inflammation in the air sacs in your lungs, which are called alveoli. The alveoli fill with fluid or pus, making it difficult to breathe. In the present study, mortality was $40 \%$. This more or less agreed with Abdel Aziz et al. (2016) who found $46.7 \%$ mortality in patients with microorganisms, which was $55.6 \%$ in $S$. aureus and $27.3 \%$ in $S$. pneumonia CAP patients. Also, the poly-antimicrobial therapy ( $>2$ antibiotics) was a predictor of mortality as patients given $>2$ antibiotics were in the bad need of the broader spectrum of antibiotic mortality as compared to those patients on one antibiotic (Zilberberg, 2010).

In the present study, prognostic factors in the community-acquired pneumonia patients were ten independent death predictors included the male sex, diabetes mellitus, malignancy, neurologic disease, tachypnea, hypotension, hypothermia, leucopenia, bacteremia, and multi-lobar infiltrates. This agreed with risk factors between survivor and non survivors (Mohan et al, 2019). No doubt, the inappropriate antibiotic treatment was a risk factor for CAP, especially caused by Legionella pneumophila or Chlamydia pneumonia (Bermejo-Martin et al, 2017), which agreed with the present outcome data.

In the present study, CAP underweight was a risk factor due to nutritional deficiency or pneumonia affected immune system. This agreed with Hedlund et al. (1995) who found significant difference between patients regarding to body mass index.

In the present study, age, smoking, malnutrition, CAP, chronic bronchitis/ COPD, asthma, functional impairment, immunosup- pressive therapy and oral steroids were definitive risk factors for CAP. This agreed with Jordi et al. (2017) who found that smoking was risk factor pneumonic males due to Legionella pneumophila, and aging for the CAP patients (Farr et al, 2000), chronic bronchitis, COPD, and asthma (Almirall et al, 2010).

Undoubtedly, chronic liver diseases were risk factor for the CAP (Fernández-Solá et $a l, 1995)$ as well as heart disease; especially congestive heart failure was association between 92\% pneumococcal infections (Lipsky et al, 1986). To treat such severe CAP cases with low dose corticosteroids was risky as they caused severe pulmonary infections due to immunosuppressive effects (Ruiz et $a l, 1999)$. Besides, the mortality rate (55\%) was higher among CAP patients who required mechanical ventilation (Yoshimoto et $a l, 2005)$. Physicians should target smoking individuals particularly those with COPD, asthma, heart disease or diabetes mellitus, and those who smoke, for pneumococcal vaccination at the earliest opportunity at any time a year (Torres et al, 2015). Wunderink and Waterer (2017) stated that pneumonia care bundles were being defined to improve the outcomes. They added that the increased recognition of both acute and long term cardiac complications was shifting the concept of pneumonia from an acute lung disease to a multisystem problem with adverse chronic health consequences.

Again, the present diabetes mellitus cases were not associated with severe CAP especially insulin dependent patients, which agreed with Reyes et al. (2017). Thus, association between pneumonia and previous upper respiratory tract infections due to influenza and other viral infections was fatal (Ge et al, 2019)

\section{Conclusion}

The range of risk factors and underlying the medical conditions were associated with an increased risk of CAP in adults.

Understanding of the types of individual at greatest risk of CAP can help to ensure that 
interventions to reduce the risk of infection and burden of disease are in need to reduce the mortality and cost of treatments.

\section{References}

Abdel Aziza, O, Mohammad, T, Abdel Fattah, A, Ahmed, HM, 2016: Mortality predictors in patients with severe community-acquired pneumonia requiring ICU admission. Egypt. J. Bronchol. 10: 155-65.

Almirall, J, Bolíbar, I, Serra-Prat, M, Palomera, E, Roig, J, et al, 2010: Community-acquired pneumonia in Catalan Countries: Inhaled drugs as risk factors for community-acquired pneumonia. Eur. Respir. J. 36:1080-7.

Alotair, A, Alhusein, M, Elhoseny, M, 2015: Severe pneumonia requiring ICU admission:

Revisited. J. Taibah Univ. Sci. 10, 3:293-9.

Bermejo-Martin, J, Cilloniz, C, Mendez, R, Almansa, R, Cabarrus, A, et al, 2017: Lympho penic community acquired pneumonia (LCAP), an immunological phenotype associated with higher risk of mortality. J. Biol. Med. 24: 231-6.

Blot, S, Koulenti, D, Dimopolos, G, 2014: Prevalence, risk factors, and mortality for ventilator-associated pneumonia in middle-aged, old, \& very old critically Ill patients. Crit. Care Med. 42, 3:601-9.

Brochot, A, Guilbot, A, Haddioui, L, Roques, C, 2017: Antibacterial, antifungal, and antiviral effects of three essential oil blends. Microbiologyopen 6, 4:e00459. doi: 10.1002/mbo3.459.

Brower, RG, Lanken, PN, Macintyre, N, Matthay, MA, Morris, A, et al, 2004: Higher versus lower positive end-expiratory pressures in patients with the acute respiratory distress syndrome. N. Engl. J. Med. 351:327-36.

Dellinger, RP, Levy, MM, Carlet, JM, Bion, J, Parker, MM,et al,2008: Surviving sepsis campaign: International guidelines for management of severe sepsis and septic shock. Int. Care Med. 34:17-60.

Estenssoro, E, Dubin, A, 2016: Acute respiratory distress syndrome. Medicina (B Aires). 76, 4:235-41

Farr, BM, Bartlett, CLR, Wadsworth, J, Miller, DL, 2000: Risk factors for community-acquired pneumonia diagnosed upon hospital admission. Respir. Med. 94:954-63.

Fekih, HM, Ayed, S, Ben-Sik, AH, Gharbi, R, Marghli, S, et al, 2009: Duration of antibiotic therapy for ventilator associated pneumonia:
Comparison of $7 \& 10$ days: A pilot study. Ann. Fr. Anesth. Réanim. 28:16-23.

Fernández-Solá, J, Junqué,A, Estruch, R, Monforte, R, Torres, A, et al,1995: High alcohol intake as a risk and prognostic factor for community-acquired pneumonia. Arch. Int. Med. 155:1649-54

Franco, J, 2017: Community-acquired pneumonia. Radiol. Technol. 88, 6:621-36.

Ge, YL, Liu, CH, Rana, MA, Zhu, XY, Wang, N, et al, 2019:Elevated red blood cell distribution width combined white blood cell in peripheral blood routine have a better sensitivity than CURB 65 scores in predicting ICU admission and mortality in the adult community-acquired pneumonia patients. Clin. Lab. 45, 4:1-3.

Hedlund, J, Hansson, LO, Ortqvist, A, 1995:

Short- and long-term prognosis for middle-aged and elderly patients hospitalized with community-acquired pneumonia: impact of nutritional and inflammatory factors. Scand. J. Infect. Dis. 27:32-7.

Hooven, TA, Polin, RA, 2017: Pneumonia. Semin. Fet. Neonat. Med. 22, 4:206-13.

Jordi, A, Mateu, SP, Ignasi, B, Valentina, B, 2017: Risk factors for community-acquired pneumonia in adults: A systematic review of observational studies. Respiration 94:299-311

Kalil, AC, Metersky, ML, Klompas, M, Muscedere, J, Sweeney, DA, et al, 2016: Executive summary: management of adults with hospitalacquired and ventilator-associated pneumonia: Clinical Practice Guidelines by the Infectious Diseases Society of America and the American Thoracic Society. Clin. Infect. Dis. 63:575-82.

Kamath, AV, Myint, PK, 2006: Recognizing and managing severe community acquired pneumonia. Br. J. Hosp. Med. 67, 4:76-8.

Liapikou, A, Ferrer, M, Polverino, E, Belasso, V, Esperatti, M, et al,2009:Severe communityacquired pneumonia: Validation of the Infectious Diseases Society of America/American Thoracic Society guidelines to predict an intensive care unit admission. Clin. Infect. Dis. 48:377-85. Lipsky, BA, Boyko, EJ, Inui, TS, 1986: Risk factors for acquiring pneumococcal infections. Arch. Intern. Med.146:2179-85.

Lim, WS, Macfarlane, JT, Boswell, TC, 2001: Study of community acquired pneumonia etiology (SCAPA) in adults admitted to hospital: Implications for management guidelines. Thorax 56: 296-301.

Lim, WS, Baudouin, S, George, R, 2009: BTS 
guidelines for the management of community acquired pneumonia in adults. Thorax 64, 3:S65. Mandell, LA, Wunderink, RG, Anzueto, A, Bartlett, JG, Campbell, GD, et al, 2007: Infectious Diseases Society of America/American Thoracic Society consensus guidelines on the management of community acquired pneumonia in adults.Clin. Infect. Dis. 44, 2:S27-30.

Ruiz, M, Ewilg, S, Torres, A, Arancibia, F, Marco, F, et al, 1999: Severe community-acquired pneumonia risk factors and follow-up epidemiology. Am. J. Respir. Crit. Care Med. 160: 923-9.

Mendez, R, Menendez, R, Cilloniz, C, Amara, I, Amaro, R, et al, 2018: Initial inflammatory profile in community-acquired pneumonia depends on time since onset of symptoms. Amer. J. Respir. Crit. Care Med. 198, 3:370-8.

Mohan, CK, Mahandra, M, 2019: Predictors of mortality in patients with respiratory infection admitted to ICU in a tertiary care centre. J. Pulmon. 3, 1:4-7.

Ranzani, OT, Coelho, L, Torres, A, 2019: Biomarkers in community-acquired pneumonia: Can we do better by using them correctly? J. Bras. Pneumol. 45, 4:e20190189.

Pugh, R, Grant, C, Cooke, RPD, Dempsey, G, 2015: Short-course versus prolonged-course antibiotic therapy for hospital-acquired pneumonia in critically ill adults. Cochrane Database Syst. Rev. 5:CD00757.

Rello, J, Rodriguez, A, Lisboa, T, Gallego, M, Lujan, M,et al,2009: PIRO score for community-acquired pneumonia: a new prediction rule for assessment of severity in intensive care unit patients with community-acquired pneumonia. $\mathrm{Cr}$ it. Care Med. 37:456-62.
Reyes, LF, Restrepo, MI, Hinojosa, CA, Soni, NJ, Anzueto, A, et al, 2017: Severe pneumococcal pneumonia causes acute cardiac toxicity and subsequent cardiac remodeling. Am. J. Respir. Crit. Care Med. 196, 5:609-20.

Torres, A, Blasi, F, Dartois, N, Akova, M, 2015: Which individuals are at increased risk of pneumococcal disease and why? Impact of the COPD, asthma, smoking, diabetes and/or chronic heart disease on community-acquired pneumonia and invasive pneumococcal disease. Thorax 70, 10:984-9

Trotter, CL, Stuart, JM, George, R, Miller, E, 2008: Increasing hospital admissions for pneumonia. Emerg. Infect. Dis. 14, 5:727-33.

Vallés, J, Martin-Loeches, I, Torres, A, 2014: Epidemiology, antibiotic therapy and clinical outcomes of healthcare-associated pneumonia in critically ill patients: a Spanish cohort study. Int. Care Med. 40, 4:572-81.

Vila-Corcoles,A, Ochoa-Gondar, O, Blanco, T, Raga-Luria, X, Gomez, F, et al, 2009: Epidemiology of community-acquired pneumonia in older adults: A population-based study. Respir. Med. 103:309-16.

Wunderink, RG, Waterer, G, 2017: Advances in the causes and management of community acquired pneumonia in adults. BMJ. Jul 10;358: $\mathrm{j}$ 2471. doi: 10.1136/bmj.j2471.

Yoshimoto,A, Nakamura, H, Fujumura, M, Nakao, S, 2005: Severe community acquired pneumonia in an intensive care unit: Risk factors for mortality. Int. Med. 44:710-6.

Zilberberg, MD, Shorr, AF, 2010: Ventilatorassociated pneumonia: The clinical pulmonary infection score as a surrogate for diagnostics and outcome. Clin. Infect. Dis. 51:S13-5. 